\title{
Genetic Rat Models of Schizophrenia-Relevant Symptoms
}

\author{
Cristóbal del Río, Ignasi Oliveras, Toni Cañete, Gloria Blázquez, Adolf Tobeña, \\ Alberto Fernández-Teruel* \\ Medical Psychology Unit, Department of Psychiatry and Forensic Medicine, Institute of Neurosciences, School \\ of Medicine, Autonomous University of Barcelona, Barcelona, Spain \\ Email: * Albert.Fernandez.Teruel@uab.es
}

Received 29 April 2014; revised 29 May 2014; accepted 12 June 2014

Copyright (C) 2014 by authors and Scientific Research Publishing Inc.

This work is licensed under the Creative Commons Attribution International License (CC BY). http://creativecommons.org/licenses/by/4.0/

(c) (i) Open Access

\section{Abstract}

It is recognized that developing valid animal models is essential for the research on the neurobiological mechanisms of (and treatments for) psychiatric disorders, even when these are as complex as schizophrenia. To be considered a valid analogue of the disorder, a given model should present good face validity (i.e. similarity of symptoms), good predictive validity (i.e. similarity of treatment effects and potential for discovering novel treatments) and enough construct validity (i.e. the model should help discover neurobiological mechanisms underlying the disorder or some relevant symptoms). The complexity of symptoms (positive, negative and cognitive) of schizophrenia makes it a very difficult task for a model to mimic all the main features of the disorder, but some rodent (mouse and rat) models have behavioural and even neurobiological phenotype characteristics resembling positive-like symptoms, cognitive symptoms and some neurochemical features of schizophrenia. As several recent works have already reviewed the main behavioural and developmental models, as well as the most used drug-induced, lesion-induced and genetic mouse models, the present review focuses on describing the most relevant genetically-based rat models of schizophrenia-relevant symptoms. Thus, we discuss several selective breeding programs leading to rat lines/strains which present impaired prepulse inhibition (PPI) of the acoustic startle response and (in some cases) latent inhibition deficits (both of which may be considered as endophenotypes of schizophrenia related with pre-attentive processes and attention, respectively), as well as other schizophrenia-relevant symptoms (e.g. learning deficits). Evidence is presented for the effects of genetic background on PPI (and other symptoms/phenotypes), as well as for environmental influences on genetic predisposition to enhanced apomorphine (mixed dopamine receptor agonist) effects. Some of the described rat models appear to present face validity and, to a certain extent, construct validity. While efforts should be made to evaluate the predictive validity of these genetic rat models, we propose that they have the advantage (over mouse knockouts, for example) of better representing "normal" genetic, neurobiological and phenotype variation,

\footnotetext{
*Corresponding author.
} 
thus allowing the study of associations among them by means of genetic mapping or gene expression studies.

\title{
Keywords
}

\author{
Schizophrenia, Genetic Rat Models, Selective Breeding, Prepulse Inhibition, Dopamine, Serotonin, \\ Glutamate
}

\section{Introduction}

After over 100 years of systematic efforts to unravel the origin of schizophrenias, the cause of these disorders remains unknown. The schizophrenias are a group of chronic mental disorders, often severely disabling, affecting about $1 \%$ of the world population. They constitute one of the major challenges for health systems and social assistance by the degree of disability and the care and expense required. They consist of a collection of signs and symptoms that are diagnosed by prototypical manifestations of mental confusion or psychosis which commonly progress towards a debilitating cognitive disorganization. The main manifestations of schizophrenia are classified into "positive" symptoms (e.g. hallucinations, delusions, thought disorders), "negative" symptoms (e.g. social withdrawal, apathy) and "cognitive" symptoms. Antipsychotic medications are often only partially successful. Around 30\% patients are unresponsive to therapy (e.g. [1]-[6]).

In the absence of definitive evidence for the molecular causes of schizophrenia, research has mostly relied on drugs as indirect tools to get knowledge on possible neurochemical mechanisms involved in the disorder. For example, if a psychostimulant dopaminergic drug induces locomotor sensitization or impairment in some excutive function (both effects are considered as analogues of some particular symptoms of schizophrenia), this suggests that dopamine may be involved in schizophrenia. Likewise, if a serotonin agonist has psychotomimetic effects (i.e. it elicits a psychotic state), this may give support to the contention that serotonin is involved in schizophrenic symptoms. If a drug that acts as a dopamine or serotonin receptor antagonist alleviates schizophrenic symptoms, then this is taken as evidence in support for a role for these particular (dopamine or serotonin) receptors/neurotransmitters in schizophrenia. Typical neuroleptics (chlorpromazine, haloperidol), block dopamine D2 receptors with potencies related to their antipsychotic effectiveness. The "dopamine hypothesis" of schizophrenia is derived from these findings (e.g. [1] [6]). The "serotonin hypothesis" of psychosis comes from the finding that hallucinogens (that mimic some positive schizophrenic symptoms), such as LSD, act as agonists at 5-HT2ARs (serotonin 2A receptors), while atypical neuroleptics (clozapine, olanzapine, risperidone; e.g. [5] [7]) are antagonists at these receptors. Some antagonists of the NMDA subtype of glutamate receptor, such as phencyclidine (PCP), also mimic schizophrenic symptoms. This, jointly with the anti-schizophrenic-like effects of some mGluR2 agonist (e.g. LY2140023) has led to the "glutamate hypothesis" of psychosis ([5]-[8]).

\section{Rodent Models and Behaviors Relevant to Schizophrenia}

Some of the most commonly used animal models of schizophrenia derive from the similarity of the human effects of psychotomimetic or psychostimulant drugs to the symptoms of schizophrenia, i.e. those animal analogues mostly reproduce positive (psychotic) symptoms. The need for more predictive and valid rodent models heralds the poor understanding we have on its precise etiology. Many human genetic studies have revealed the existence of susceptibility genes (mostly related to synaptic and glia function, neuronal growth and cortical/ subcortical circuitry development; reviews by [1] [2] [7]), while they also indicate that interactions between genetic susceptibility and environment play a prominent role (e.g. [2]). Thus, the current view of schizophrenia is that it is a poligenetic neurodevelopmental cognitive disorder with environmental influences (e.g. [1]-[3]), that cannot be reduced to its psychotic symptoms and is not just a result of abnormal dopamine (nor serotonin) functioning [9]. There is an urgent need to establish newer animal models that can take these insights from human studies into account and which show better construct and predictive validity (for developing new drugs/treatments and restoring cognitive dysfunctions of schizophrenia; e.g. [1] [2] [9]).

Moreover, the complexity and diversity of schizophrenia does not allow to focus on the entire constellation of symptoms of the disorder. Just as schizophrenic patients do not manifest every possible symptom, an "ideal" or 
"improved" animal model of schizophrenia will not necessarily present alterations in all schizophrenia-relevant symptoms/behaviors. Thus, it is clear that individual rodent behaviors (either spontaneous or induced by—for instance-a psychotomimetic drug, either conditioned or unconditioned) can not constitute models of schizophrenia by themselves. We need animal models able to recapitulate several relevant features of schizophrenia, which in turn would be of especial value if some of these features/symptoms are also linked to some susceptibility gene/s or neural alterations thought to be relevant for the disorder (e.g. [2] [3] [9] [10]).

The characteristics of some of the main behavioral models/procedures currently used to measure schizophrenia-relevant phenotypes of the three types of schizophrenia-related signs/symptoms can be summarized as follows (see also Table 1): 1) Baseline or novelty-induced hyperactivity, dopamine agonist-and psychotomimetic (phencyclidine, ketamine)-induced hyperactivity/stereotypies, are considered as signs connected with some of the positive symptoms of the disorder. 2) Altered social interaction responses (including nesting behaviour) in a variety of situations are considered as analogues related to negative-social withdrawal-symptoms of schizophrenia ([2]; Table 1). 3) Cognitive impairment in schizophrenia includes information processing, abstract

Table 1. Profile of RHA rats in models, behaviors and neural aspects relevant to schizophrenia.

Schizophrenia-relevant behavioural models/symptoms or neural phenotypes

RHA vs RLA

I. -Positive Signs/Symptoms (ref. [104] [106] [109] [114])

A. -Locomotor activity in response to novelty

B. -Sensitivity to psychotomimetic/psychostimulant drugs -Augmented locomotor/stereotypic responses to DA agonists.

-Augmented locomotor and DAergic sensitization to AMPH.

\section{II. -Negative Signs/Symptoms (ref. [115])}

A. -Decreased nesting behavior

B. -Social behavior/aggression: Resident-Intruder test

III. -Cognitive Symptoms (ref. [20] [79] [98] [99] [113] [116])

A. -Decreased working memory

B. -Deficits in attention/sensorimotor gating/executive functions -Decreased sensorimotor gating (prepulse inhibition-PPI-deficits)

-Decreased latent inhibition

-5-choice serial reaction time test (5-CSRTT)

C. -General cognitive deficits
*RHA higher locomotor response to novelty (also compared to the Sprague Dawley strain).

*RHA: higher stereotypic responses to APO (also compared to Sprague-Dawley strain) and locomotor responses to AMPH in some cases.

*RHA: enhanced locomotor and DAergic sensitization (also compared to the Sprague Dawley rat strain).

*RHA: impaired nesting behaviour (see Figure 2).

*RHA: increased aggression latency in resident-intruder test.

*RHA: impaired working memory in the delayed-matching-to-place paradigm in the MWM (also compared to the outbred NIH-HS rat stock/strain).

*RHA: impaired PPI (vs RLA and NIH-HS rats; see Figure 1)

*RHA: impaired latent inhibition threshold (compared to Sprague Dawley rat strain).

*RHA: impaired 5-CSRTT efficiency. Increased premature responses and impulsivity.

*RHA: impaired in several spatial reference learning (and explicit/declarative memory) tasks-e.g. MWM and Hebb-Williams maze and classical aversive conditioning (also compared to NIH-HS rats).

IV. -Neurochemical/neuroanatomical phenotypes linked to schizophrenia (ref. [104] [106] [107] [108] [110] [111] [113])
A. -Central DAergic function
B. -Hippocampal function and neuromorphology
C. -Serotonin and glutamate function

D. -5-HT2A/mGluR2 complex in prefrontal cortex
*RHA: increased mesolimbic and mesocortical dopamine responses to DAergic agonists or stress (respectively).

*RHA: decreased hippocampal function and reduced neuronal density in hippocampal CA fields/layers.

*RHA: enhanced expression of 5-HT2A and absence of expression of mGluR2 receptors in prefrontal cortex. Also absence of mGluR2 expression in the hippocampus and striatum.

*In comparison with the RLAs, the 5-HT2A/mGluR2 complex in RHAs resembles the profile of schizophrenic patients and mGluR2 knockout mice. 
categorization, executive function/flexibility, attention and memory (for a review see [2]). Working memory is one of the most studied in rodents, by using the 8-arm radial maze (8-ARM), delayed/spontaneous alternation tasks or the delayed matching to place task in the Morris water maze (MWM) ([11] [12]; see review in [2]). 4) Impaired explicit/declarative memory (relevant in schizophrenia) is modelled in several tasks with the MWM, the 8-ARM or odor discrimination tests (see e.g. [2]). 5) Sensorimotor gating tests/tasks model the pre-attentive processing deficits observed in schizophrenia (e.g. [2]). Prepulse inhibition (PPI; a weak stimulus—prepulsereduces the startle response to a subsequent intense startling stimulus), which measures sensorimotor gating, is decreased in schizophrenic patients. PPI in rodents is regulated by a cortico-limbic-striato-pallidal circuit (including the hippocampus) and is impaired by a variety of experimental conditions (e.g. by dopamine and serotonin receptor agonists and glutamatergic NMDA receptor antagonists; and enviromental treatments), while effective neuroleptic treatment mitigates PPI deficits ([2] [3] [9] [13]-[17]). 6) Attentional processes are also measured through "latent inhibition" (both in laboratory animals and in humans), which is deteriorated in human schizophrenic patients (e.g. [18]-[20]). 7) Another measure of attention and some aspects of executive function (thus, relevant for schizophrenia) in rodents is the five-choice serial reaction time task (5-CSRTT), which is based in measures of sustained attention used in humans (e.g. [2] [10]).

\section{Genetic Rat Models of Schizophrenia}

Recent advances in human and mouse genomics and genetic technology have led to great progress in schizophrenia research, particularly regarding its modeling in laboratory animals. Provided the high level of homology between human and mouse genes, genetic mouse models allow testing whether alteration of schizophrenia-susceptibility candidate genes leads to schizophrenia-relevant abnormalities in mice. If so, the relevance of these candidate genes can be evaluated in humans. Some examples of these models are the neuregulin 1 (NGR1) heterozygous mice, the DISC1-1 (suceptibility gene disrupted-in-schizophrenia) gene, the dopamine transporter knockout mice, the calcineurin (CN) knockout mice and the 5-HT2A and glutamate receptor knockouts used by Gonzalez-Maeso and coworkers (e.g. [5] [7]) to study the relevance of the 5-HT2A/mGluR2 complex in schizophrenia-relevant features (see reviews by [2] [3] [5] [7]). Some of these genetically-based mouse models appear to present some face and construct validity, but their predictive value still needs to be established because they have not yet generated relevant advances as concerns to new treatments.

Advances of genetic manipulation technology in the laboratory rat have progressed more slowly than in mice. Thus other strategies and models have been developed with the goal of studying schizophrenia-related features in rats.

While behavioral tests/models, drug-and lesion-induced models, developmental models and mouse genetic models have been thoroughly discussed in recent reviews (e.g. [1]-[3] [9] [10] [13] [17] [19]), genetically-based rat models have received very little attention. Thus, the aim of the present review is to discuss the most relevant aspects of some genetic approaches that have used selective breeding of rats to model schizophrenia-relevant features, as well as to describe other approaches based on existing rat strains (either selectively bred or not) which present behavioral and/or neurobiological profiles relevant to the disorder.

\subsection{Genetic Background Effects on PPI Phenotypes Using "Standard" Rat Strains}

Although schizophrenia is considered as a mental disorder associated with polygenetic causes, there is consensus that environmental factors contribute to the onset of the disease. However, in order to understand the underpinnings of some relevant pre-cognitive (such as sensorimotor gating-PPI-) and cognitive phenotypes, it may be critical to try to better discriminate whether genetics or environment (or their interaction) are involved, for instance, in sensorimotor gating phenotypes.

The literature shows that there are significant strain and substrain differences in both "basal" levels of PPI and in sensitivity to the PPI-disruptive effects of pharmacologic agents, such as dopamine (DA) agonists [21] [22]. In this regard, it has been reported that Sprague-Dawley rats from Harlan Laboratories ("SDH" rats) showed greater sensitivity to apomorphine (APO)-induced PPI disruption than Wistar rats from the same laboratory ("WH" rats), and similar differences were observed between Sprague-Dawley and Wistar rats from BantinKingman Laboratories (see reviews by [22]-[28]). However, environmental factors might contribute to some of the observed differences in PPI drug sensitivity, as there are reports indicating effects of developmental/environmental factors on adult levels of PPI (e.g. [29] [30]). 
Differential drug sensitivity in rats with similar genetics but coming from different breeding facilities might reflect (or might be produced by) subtle differences in the rearing environment. Some startle measures, and the behavioral sensitivity to DA agonists, are also known to be influenced by stressors, as indicated, for example, by a study conducted with the APO-SUS and UN-SUS rat lines and their responses to environmental changes or stressors ([31], see also [32]). Then, it is conceivable that differential PPI drug sensitivity in rats from different facilities might be influenced by environmental factors and/or stress associated with different rearing environments and/or different forms of transportation from the breeding facilities to the testing locations.

A study tested the hypothesis that genetic background plays a major role among the different factors that might contribute to strain and substrain specific patterns of sensitivity to the PPI-disruptive effects of DA agonists in rats [26]. In this study, Sprague-Dawley rats from nearly identical gene pools, raised in three different facilities (Indianapolis-SDHi rats-, Texas-SDHt rats- and San Diego-SDHsd rats-), were compared to the Long-Evans strain ("LEH", from Harlan Laboratories). Travel for both the SDHi and SDHt substrains to the testing laboratory in San Diego (USA), via air freight, yielded comparable levels of stress. The objective was to characterize the PPI-disruptive effects of several DA agonists in SDHi and SDHt rats, and compare them to the PPI-disruptive effects of these drugs in the genetically distinct LEH strain (shipped to San Diego via air freight from Madison, WI, USA). Sensitivity was assessed using the mixed D1/D2 agonist APO, as well as the relatively selective D1-family agonist quinpirole, and full D1 agonist SKF 82958. These results were also compared with those obtained in SDHsd rats (from Harlan Laboratories, San Diego) from a local supplier facility, without the potential impact of air freight transportation [26]. Results showed that outbred Sprague-Dawley rats from the different facilities-SDHi and SDHt—exhibited very similar PPI sensitivities to the effects of APO, quinpirole and SKF 82958. These patterns were also similar to those exhibited by the San Diego Sprague-Dawley substrain (SDHsd rats) that did not pass through the air freight. But the patterns observed in the SDH rats in APO sensitivity differed significantly from those exhibited by Long-Evans rats. Thus, PPI sensitivity to APO did not differ significantly among genetically similar rats reared in different facilities and transported via different methods (SDHi vs SDHt vs SDHsd), but differences were found among genetically different rats transported to testing location via similar methods and associated stressors (SDHi/SDHt vs LEH [26]). These results suggested a role of genetic background in sensorimotor gating, despite environmental influences [26].

The authors made a further step in the evaluation of genetic background influences on the PPI-disruptive effects of APO. Taking into account that SDH rats are more sensitive to these drug effects than LEH rats, the authors carried out a cross-breeding experiment in which they crossed SDH $\times$ LEH rats to obtain a "F1" generation, which was in turn back-crossed to SDH rats, giving a "N2" generation. The study showed clear cut results concerning APO-induced disruption of PPI, which was maximal in SDH and minimal in LEH rats (with significant differences between them), while F1 and N2 generations displayed intermediate values (which differed from those of SDH and LEH rats) [23] [24]. Using the same kind of generational procedure the authors also tested the PPI-disruptive effects of amphetamine (AMPH; indirect DA agonist) and DOI (5-HT2A receptor agonist). The results of AMPH-induced PPI disruption followed a gradient of SDH > N2 > F1 > LEH, very similar to the effects of APO (see above), while no differences across generations were found with regard to DOI effects [27]. Altogether the previous studies suggest a pattern of heritable DA-related PPI phenotypes, while there is no evidence for such a genetic component in 5-HT-mediated effects on PPI [23] [24] [27].

The potential role of non-genomic factors on the APO sensitivity (PPI) phenotype was assessed in a cross fostering study with SDH and LEH rats. There was no significant "strain $\times$ foster strain" interaction on APO effects on PPI, but SDH pups reared by LEH mothers displayed a significantly increased SDH phenotype of disrupted PPI [24]Therefore, the phenotypical strain differences cannot be explained on the basis of maternal behavior, even if some particular strain (i.e. genotype) may be sensitive to some environmental influence/factor.

\subsection{Differences among Other Rat Strains in Schizophrenia-Relevant Symptoms}

\section{1) Brattleboro rats}

The Brattleboro rats (BRAT) are Long Evans (LE)-derived rats with a single mutation that impairs vasopressin release [33]. BRAT rats display an innate deficit of PPI [34]-[39]. Berquist et al. [38] hypothesized that such deficit may compromise performance, in tasks assessing attention, by diminishing the ability to shift attention between stimuli. Interestingly, of relevance for the predictive validity of the BRAT rat strain is the fact that a wide range of antipsychotics, such as haloperidol, clozapine and risperidone (olanzapine had a less robust effect), 
reversed the deficits in PPI. Still relevant to model positive symptoms, Cilia et al. [39]showed that BRAT rats are hyperactive and show increased startle response and decreased levels of DA in the prefrontal cortex as compared to Long Evans rats.

Other studies, comparing BRAT and LE rats, have also reported cognitive deficits, such as impaired fear conditioning, impaired acquisition and maintenance of passive avoidance behavior and deficits in spatial learning in a delayed alternation task [38]. Moreover, Feifel et al. [35] showed that BRAT rats presented a natural deficit in social discrimination, as they spent a comparable amount of time exploring a novel and a familiar rat. The authors interpreted that such an impaired social discrimination is due to a deficit in social memory rather than a nonspecific reduction in general activity or in social motivation, because saline-treated BRAT rats and LE rats spent almost the same time interacting with a juvenile rat during the acquisition phase. Berquist et al. [38] reported recently that male BRAT rats employed more time (16.8\% longer) than LE rats to complete a task based on the 5-choice serial reaction time (5-CSRT) task, while there were no between-strain differences in females.

There are, however, controversial results, as Brito et al. [40] reported no significant differences between BRAT rats and LE rats neither in a delayed alternation task in the T-maze nor in a visual and olfactory discrimination task. Likewise, Laycock et al. [41] even found that BRAT rats needed fewer sessions to learn a positively reinforced operant conditioning task.

BRAT rats also present interesting neurochemical features, such as D2 receptor up-regulation in the nucleus accumbens shell and dorsomedial caudate putamen [39]. It has been suggested that this feature is due to a compensatory response for the low levels of DA function [39] [42].

2) The Spontaneous Hypertensive Rat (SHR)

The Spontaneous Hypertensive Rats (SHR) were derived from Wistar Kyoto rats (WKY) and they were introduced in the 1960s as a genetic model for hypertension. Several studies have shown that the level and turnover of catecholamines in SHR rats are imbalanced. Particularly, dopamine has been suggested to have an important role in the development of hypertension. SHR rats have also been proposed as a model for AttentionDeficit Hyperactivity Disorder (ADHD) [43] [44]. They show hyperactivity, attention deficits and impulsivity, but, contrary to ADHD, dopamine agonists do not improve these symptoms in SHR rats (e.g. [45] [46]). Such findings constitute a main problem to consider the SHR rat as a model for ADHD.

Another line of research with the SHR rats has focused on the behavioural outcome produced by dopaminergic agonists and antagonists and the possible validity of that rat strain as a model of schizophrenia-relevant symptoms. In this regard, compared to the WKY strain SHR rats present PPI deficits at different prepulse intensities (e.g. [47] [48] but see controversial results in [49]). Importantly, some of the symptoms of SHR rats are decreased [45] [46] [50] by antipsychotics and increased by amphetamine.

Calzavara et al. [45] [46] have proposed to study emotional context processing with contextual fear conditioning, as they have proved that SHR rats have deficits in this task. In addition, SHR rats also exhibit impaired social interaction [45] [51] that is specifically reversed by atypical antipsychotics and enhanced by amphetamine [45].

3) Conclusion

There are contradictory findings with the BRAT and SHR strains with regard to their validity as models of schizophrenia. For instance, Ferguson and Cada [47] reported that SHR rats showed better spatial learning performance in the Morris water maze than SD and WKY rats. In addition, with both the BRAT and SHR strains there are studies that show PPI deficits [37] [39] [48] but other studies do not show these deficits [49] or the low number of subjects used could preclude to draw definitive conclusions [47]. The results concerning the cognitive and emotional deficits modeled by the two rat strains might appear as being even more consistent than PPI findings. Remarkably, these cognitive and emotional deficits are generally reversed by atypical antipsychotics. To sum up, further research is needed on the BRAT and SHR rat strains to overcome those relatively controversial findings and to consolidate their possible validity to model schizophrenia-relevant symptoms.

\subsection{Selective Breeding of Reduced Sensorimotor Gating: The Low- and High-PPI Rat Lines}

This animal model is based on selective breeding (derived from Wistar rats) for high/low sensorimotor gating, as measured by prepulse inhibition (PPI) of the acoustic startle response (ASR). Since PPI is a measure of sensorimotor gating which presents good translational value (i.e. it can be measured in humans using the same procedures as in rodents), experimentally induced PPI deficits in rats are regarded as an endophenotype to study the biological mechanisms of schizophrenia (and other neuropsychiatric disorders) as well as to evaluate new thera- 
peutic strategies. Bidirectional selection/breeding of rats according to their particularly high or low PPI levels, has led to two rat lines which clearly differ in PPI performance in a stable manner across generations [52] [53]. Thus, studies with these rat lines show that the measure of PPI and startle responses over 6 generations resulted in a clear-cut segregation, with the low-PPI line showing reduced PPI throughout all generations and showing no overlap with PPI measures from the high-PPI line. Interestingly, these differences were present at all prepulse intensities (68, 74, 80, $86 \mathrm{~dB})$. ASR levels, as measured in pulse alone trials, were also different, with the lowPPI rat line showing enhanced ASR (reaching significance in the $3^{\text {rd }}, 4^{\text {th }}$ and $6^{\text {th }}$ generations [52] [53]). With regard to the ontogeny of those line differences, it is remarkable that PPI deficits in the low-PPI line are found already at weaning (postnatal-PND—day 21), while the increased ASR magnitude is only evident at puberty (from PND 35). On the other hand, PPI significantly increases with age in the high-PPI rat line, but there is no increase in the low-PPI line [52] [53].

The fact that PPI levels are sensitive to bidirectional selection of high and low rat lines/strains, in conjunction with the observations that stable individual differences (across time) in PPI exist and that unaffected relatives of schizophrenia patients also show PPI deficits, has led to the suggestion that the PPI endophenotype has a relevant genetic component (e.g. [26] [52] [53]).

Although PPI performance is considered to be an endophenotype of schizophrenia, it is important to evaluate whether this phenotype is accompanied by other schizophrenia-relevant symptoms. For this purpose, Freudenberg et al. [52] evaluated the low-and high-PPI rat lines in different spatial and operant learning paradigms, in order to assess their learning and memory abilities as well as their behavioral flexibility. First, rats were tested in the four-arm baited eight-arm radial maze task, which provides measures of both reference and working memory. They were consecutively trained in an egocentric and an allocentric learning strategy in the same maze. Thereafter, rats had to switch between these two paradigms to assess their behavioral flexibility. Finally, rats were tested in several operant tasks with different response demands [52]. The main finding of this study was that low-PPI rats showed enhanced perseveration in both spatial and operant tasks for behavioral flexibility, while learning and memory were overall not disturbed [52]. In fact, increased perseveration in the low-PPI rat line was reflected as an impairment to switch from the egocentric to the allocentric strategy. According to the authors, the low-PPI rat line may appear to have, 1) a deficit in the retrieval of previously learned information to solve the allocentric strategy, and/or 2) a disturbed ability to suppress the previously rewarded egocentric behavior [52]. It has been proposed that the striatum is implicated in egocentric behavior, while the hippocampus appears to have a main role in allocentric responses [54]-[56]. Interaction between these regions seems to play a critical role for switching between egocentric and allocentric strategies [57]. All the previous evidence has led the authors to suggest that the low-PPI rats may have hippocampal and/or striatal deficits underlying their perseverative behavior [52].

In accordance with the findings from the previous task, in the operant behavioral paradigm for behavioral flexibility the low-PPI rats were less able (always compared with the high-PPI line) to adjust their behavior to changing reward values. The described phenotypic profile of selected low-PPI rats, showing increased perseveration responses in different tasks, mimics similar schizophrenic symptoms, as perseveration is one of the most consistent findings observed among schizophrenia patients while performing the Wisconsin Card Sorting Test (WCST), whereas usually there are no deficits in global cognitive function [58] [59].

Deficits in social behavior and motivation have also been reported in the low-PPI rats [60], thus even supporting their validity as a model for some negative symptoms of schizophrenia. Moreover, haloperidol, but not clozapine, has been found to reverse the PPI deficits of that rat line [61].

It is outstanding that although differences between low-PPI and high-PPI rats in dopamine-2 receptors have not been demonstrated, the low-PPI line displays decreased neuregulin-1 (NGR1) methylation in schizophreniarelated brain regions [62]. This finding is consistent with phenotypes found in schizophrenia patients [63] and with previous results showing that rats expressing elevated brain NRG1 levels are usually impaired in PPI [28].

To sum up, the behavioral differences and these neurochemical/epigenetic findings point to rats selectively bred for low PPI as a very promising genetic model that can be used to study the pathophysiology of disorders such as schizophrenia, and also to evaluate new therapeutic strategies.

\subsection{Wistar Rats Selectively Bred for Tail Flick, PPI and Novel Object Recognition}

Petrovszki et al. [64] have developed a psychogenetic breeding program in which Wistar-derived rats were treated with ketamine for 15 days (from 5 to 7 weeks of age) at the same time that they were reared in isolation. 
When 9 weeks old the rats were evaluated in the tail flick test (sensitivity to acute heat pain). Rats of both sexes presenting the highest pain threshold were selected for the selective breeding program in the $1^{\text {st }}$ and $2^{\text {nd }}$ generations. From the $3^{\text {rd }}$ generation the rats were also tested for PPI at 10 weeks of age, so that those with the highest pain thresholds and lowest PPI levels were selected for the next breeding generations. From the $6^{\text {th }}$ generation rats were additionally tested for novel object recognition (NOR) at 11 weeks of age. Since then, $5-7$ rats of each sex presenting impaired pain sensitivity (i.e. long tail flick latencies), low PPI levels and deficits in the NOR task were selected for further selective breeding to generate a new rat line aimed to model schizophrenia-relevant symptoms [64].

Besides selecting the rats for their scores in the three tests mentioned above, the authors have tested whether the selective breeding alone (i.e. without any further treatment; i.e. "Selectively bred-Untreated", as they are named by the authors) induces schizophrenia-relevant behavioral effects that are further increased by adding chronic ketamine and social isolation treatments. That is to say, are the "Selectively bred-Untreated" rats equally or less impaired than the "Selectively-bred-Treated" rats? ("Treated" means ketamine and social isolation treatments). The authors found that the selectively bred groups (both "Treated" and "Untreated") displayed lower PPI levels than their non-selected—control—counterparts, while ketamine and social isolation treatments did not add any further deleterious effect. So, the authors argued that the genetic background (i.e. the effect of selective breeding) has a more relevant role in the outcome of this test than both the treatments used (i.e. ketamine and social isolation) [64].

Regarding the NOR test it was found that both "Treated" groups and both "Selectively bred" groups presented impairments with respect to "Naive-Untreated" rats [64].

The authors interpret their results as showing the importance of selective breeding as a method for the assessment of complex traits influenced by genes and environmental factors. The present psychogenetic model, of which there is at present some good evidence on its face validity, appears to be a potentially promising one to study schizophrenia-relevant features.

\subsection{The APO-SUS and APO-UNSUS Rats}

Another genetically-based animal model of schizophrenia is constituted by the apomorphine susceptible (APOSUS) and unsusceptible (APO-UNSUS) rats, based on the bidirectional selection for extreme gnawing responses to the dopaminergic agonist apomorphine [65] [66]. The authors found that as a consequence of that selection these two rat lines also presented a bimodal distribution of a number of different behaviors, such as responses in a resident-intruder test, novelty-induced responses and in dopamine agonist-induced stereotypies. Moreover, these animals show clear differences in their endocrine and immunological systems. APO-SUS rats are characterized as having a hyper-reactive hypothalamus-pituitary-adrenal axis compared to APO-UNSUS [67].

It is known that the behavioral response to dopaminergic drugs is determined, at least in part, by genetic factors (see also Section 3.1). In mice, evidence for six different quantitative trait loci (QLT) were found to contribute the variation in apomorphine-induced climbing [68]. In rats, the possible involvement of genes has usually been studied by investigating stock/strain differences as well as individual differences within the same stock/strain. In a study carried out with the aim of exploring whether genetic factors contribute to apomorphine susceptibility, a cross-breeding design was used, i.e. APO-SUS males were mated with APO-UNSUS females and vice versa. Results show that the hybrid rats (i.e. offspring from APO-SUS $\times$ APO-UNSUS crosses) displayed gnawing scores in between the parental APO-SUS and APO-UNSUS lines [69], thus lending support to the existence of relevant genetic factors influencing apomorphine susceptibility.

However, there is also evidence that non-genetic/environmental factors play a role in determining the phenotypical expression of apomorphine susceptibility. Thus, cross-fostering (i.e., changing the dams immediately after birth) was found to reduce apomorphine susceptibility in cross-fostered APO-SUS rats (reared by APO-UNSUS dams) to the level of control (in-fostered) APO-UNSUS rats, whereas maternal deprivation (i.e., a single $24 \mathrm{~h}$ separation of the mother from her pups) increased apomorphine susceptibility in APO-UNSUS rats. Interestingly, cross-fostering did not affect apomorphine susceptibility in APO-UNSUS rats, and maternal deprivation did not affect apomorphine susceptibility in APO-SUS rats [69]. Thus, it appears that the genetic background of the rats determines how the individual responds to early environmental stressors, and that it is the interaction between these genetic factors and early environmental influences what determines the phenotypical expression of the genotype [67] [68]. 
It is well documented that the APO-SUS rats show diminished prepulse inhibition of the acoustic startle response (PPI) compared to their APO-UNSUS counterparts, although the difference is only present at low prepulse intensities (72 dB and $74 \mathrm{~dB}$ ) [66]. Moreover, these APO-SUS rats show impaired latent inhibition in a conditioned tasted aversion paradigm compared to APO-UNSUS rats [66]. It has been suggested that the above mentioned PPI and attentional deficits could be due to alterations that APO-SUS rats present in central catecholaminergic nigrostriatal and limbic systems, including increased levels of mRNA for tyrosine hydroxilase, increased density of dopamine D1 receptors and enhanced dopamine release in the nucleus accumbens. Further supporting the enhanced catecholaminergic activity of APO-SUS rats, they have been shown to be more sensitive to the locomotor-stimulating effects of amphetamine (AMPH [67] [70]), as well to the disruption of PPI induced by AMPH or cocaine [67] [70] [71]. The latter effect is counteracted by the D2 receptor antagonist remoxipride [71].

There is less information concerning differences between the two rat lines in other central structures and neurotransmitter systems, although it is remarkable that APO-SUS rats show increased metabolic activity in the hippocampus, as well as lowered levels of dynorphin-B in the same area (e.g. [67]). However, further systematic pharmacological (including atypical antipsychotic drugs) and neurochemical studies pointing to central serotonin and glutamate transmission would be desirable in order to get a more complete picture on the validity of APO-SUS/APO-UNSUS as tools to study schizophrenia symptoms and mechanisms.

\subsection{The Roman High-Avoidance (RHA) and Low-Avoidance (RLA) Rat Lines/Strains}

Another genetically-based rat model for schizophrenia-relevant phenotypes is constituted by the RHA (Roman High-Avoidance) and RLA (Roman Low-Avoidance) rat strains/lines, bidirectionally (psychogenetically) selected for their rapid v/s extremely poor (respectively) acquisition of the two-way active avoidance response [72]-[84].

A wealth of evidence has accumulated over the years concerning stress sensitivity and anxiety/fearfulness profiles of the RLA and RHA lines/strains. The main conclusions are that the RLAs show elevated levels of hormonal responses (ACTH, corticosterone and prolactin) to stress (see [74] [76] [82] [85]-[87]) as well as enhanced levels of anxiety/fear as measured in different unconditioned tests (e.g. "timidity" tests, open-field test, hole-board test, elevated plus-maze and elevated zero-maze tests, several light/dark tests, baseline acoustic startle response [76] [78] [82] [84] [86]-[93]) and conditioned [82] [83] [91] [92] procedures/tasks. In line with that, RLAs are also characterized by increased "frustration" responses in several procedures involving reduction of expected rewards (negative contrast; e.g. [94]) and by a lowered central GABA-A/benzodiazepine complex function (which is known to be critically involved in the regulation of anxiety/frustration [95] [96]).

Interestingly, in particular for the consideration of schizophrenia-relevant features in RHA rats, this strain/line presents impaired acquisition and retention of fear conditioning in different paradigms [79]-[82] [91] [92] [97], and worsened performance in spatial reference and working memory tasks [98]-[101] as well as in non-spatial tasks [102] [103]. The RHA rat line/strain has also been shown to display enhanced impulsive behavior in the 5-CSRTT and DRL-20 operant tasks [102] [103]. These profiles suggest that RHA rats may have some value for modeling certain deficits of executive function present in schizophrenia.

Compared with the RLA line/strain, RHA rats also show increased locomotion under novelty situations, preference for novelty and for drugs of abuse or rewarding substances [76] [94] [104]-[106], deficits in latent inhibition threshold [20], augmented mesocortical dopaminergic response to stress [107], enhanced locomotor as well as mesolimbic dopaminergic sensitization to repeated (DAergic) psychostimulant administration (see [106] [108] [109]), and neurochemical and neuromorphological evidence of decreased hippocampal function [110][112]. Thus, the RHA rat line/strain appears to fulfill many of the criteria required for a model of schizophreniarelevant symptoms with face and some construct validity (see Table 1 ).

With the aim of broadening the characterization of this strain rat as a valid model for studying schizophrenia, we recently conducted a study which intended to evaluate, from a developmental standpoint, whether RHA rats also resemble schizophrenic patients with respect to sensorimotor gating (i.e. PPI) deficits. Thus, in this experiment we tested inbred RHA-I and RLA-I male rats in the PPI paradigm at postnatal days 30, 50 and 100 (PND30, PND50 and PND100, respectively). One of the characteristics of schizophrenia is a long latency until its full manifestation, which mostly occurs in post-adolescence/early adulthood. We found that there were no 
between-strain significant differences in PPI at PND30 and PND50, but there were significant differences in 100-day-old rats, with RHA-I rats displaying clear PPI deficits compared to RLA-I animals (see Figure 1).

Interestingly, similarly to what has been observed in humans, the PPI deficit of RHA-I rats is present at each of the four prepulse intensities (65, 70, 75 and $80 \mathrm{~dB}$ ) used (e.g. see [3] [4]). Moreover, perhaps related with negative symptoms of schizophrenia, RHA-I rats display worsened nesting behavior (see Figure 2). These findings can be interpreted as further supporting the validity of RHA-I rats as a model of schizophrenia relevant symptoms.

Although there exists wide evidence relating schizophrenia and dopamine function, as discussed in different sections of the present work and in part of the cited literature, an outstanding example of a combined genetic, neurobehavioral and pharmacological approach leading to the discovery of new neurochemical mechanisms with great potential relevance for schizophrenia is provided by recent work from Gonzalez-Maeso's group and others (e.g. [5]-[7] [13]). These authors have demonstrated that 5-HT2A and mGluR2 cortical (prefrontal) receptors form a physical functional complex (named 5HT2AR/mGluR2 complex), which is related to several schizophrenic symptoms in mice (they have used 5-HT2A and mGluR2 knockout mice), to hallucinogenic drug effects and to atypical antipsychotic drug therapeutic actions. The 5HT2A/mGluR2 complex triggers unique
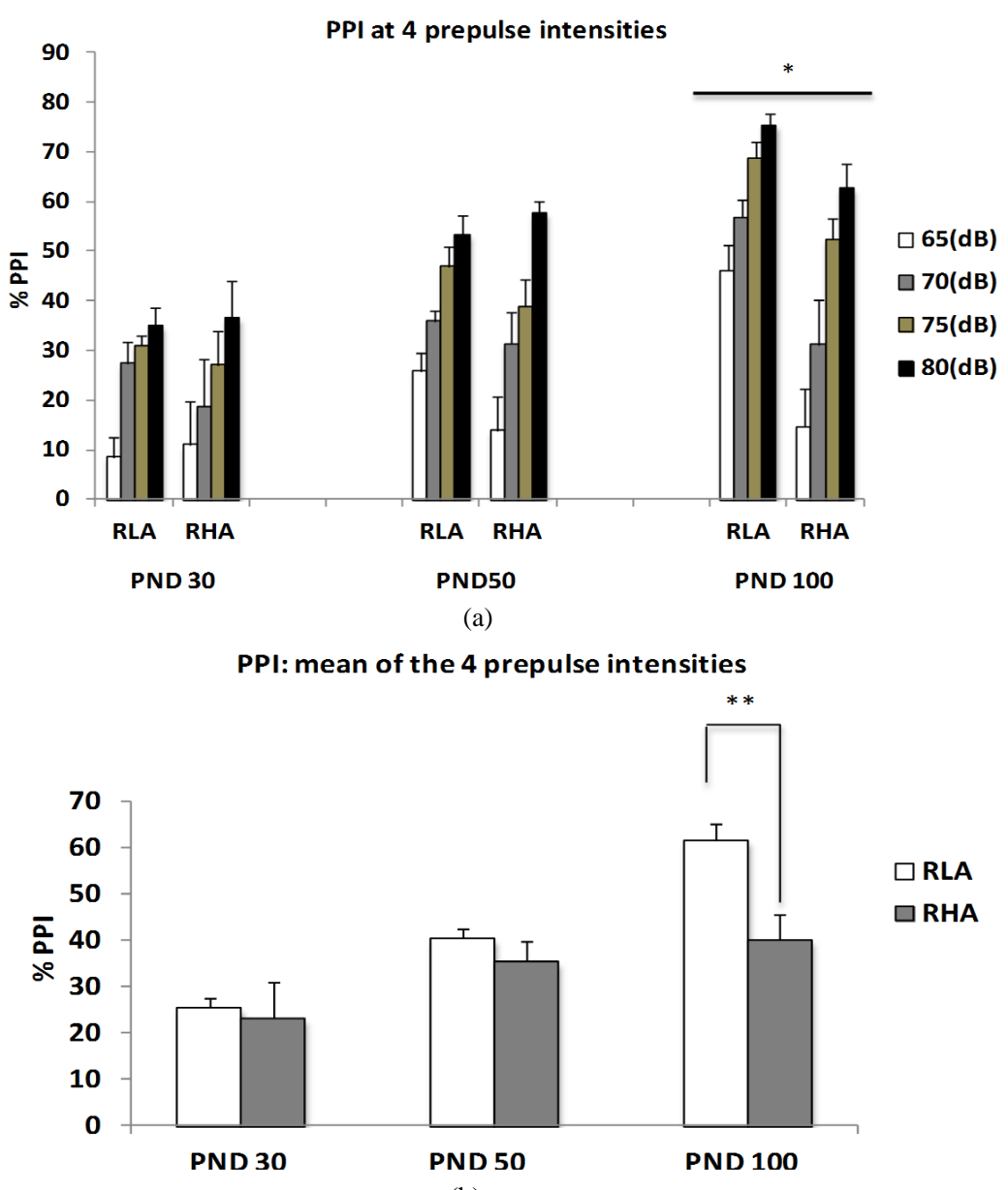

(b)

Figure 1. (a) Means \pm SEM of \%PPI values at the different ages (postnatal days, PND; PND30—n = 8/group-, PND50—n = 10 - 15-, PND100—n = 20/group-) and prepulse intensities $(65,70,75,80 \mathrm{~dB})$ between male RHA-I and RLA-I rats; (b) Means \pm SEM of "mean \%PPI" values collapsed for the four prepulse intensities (i.e. "mean \%PPI" $=(($ PPI $65 \mathrm{~dB}+$ PPI $70 \mathrm{~dB}+$ PPI $75 \mathrm{~dB}+$ PPI 80 $\mathrm{dB} / 4)$ ). *Significant differences between the strains at the four prepulse intensities, all $F s \geq 5.52$ and all $\mathrm{p} \leq 0.01$ (ANOVA). ${ }^{* *} \mathrm{p}<0.002(\mathrm{~F}(1,38)=11.6)$ between both groups/strains. 


\section{Impaired nesting behavior in RHA-I.}

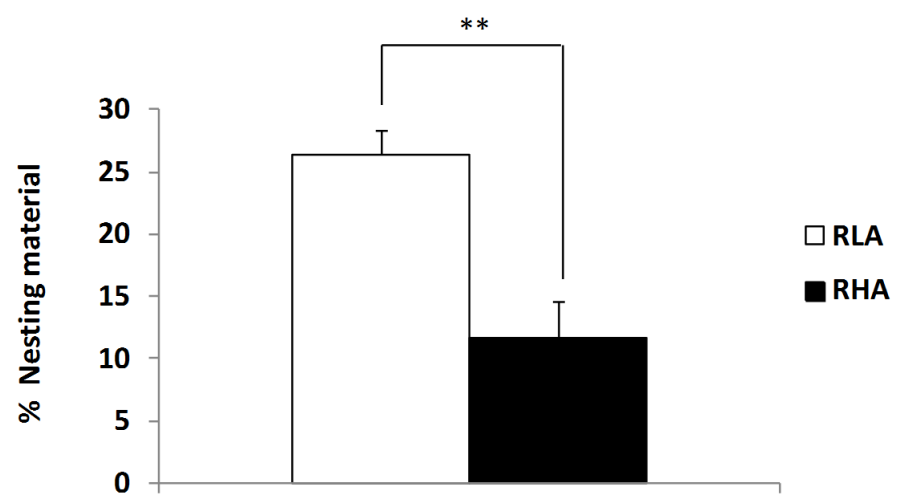

(a)

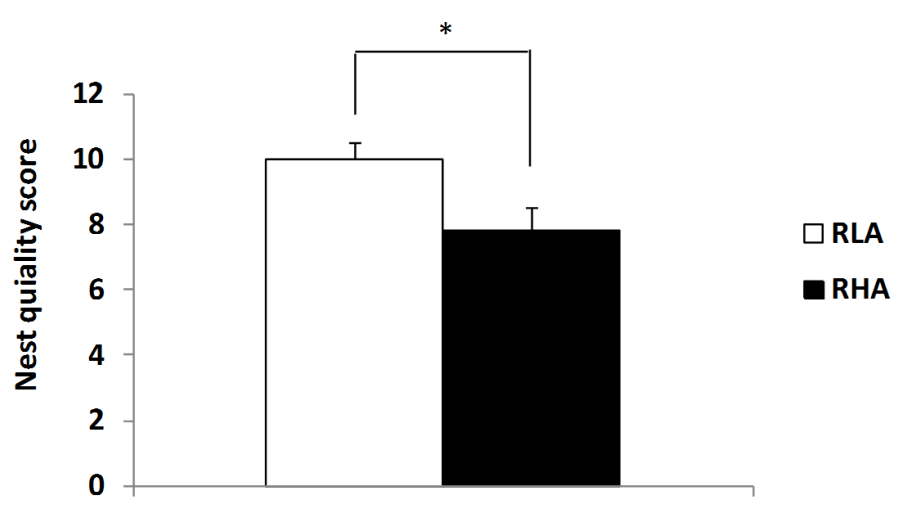

(b)

Figure 2. (a) Means \pm SEM of percentage of nesting material used for nest building by RLA-I and RHA-I mother rats; (b) Accumulative score (of 5 measures, 2 pre-natal and 3 postnatal assessments) of quality of the nest measured according to a 0 - 4 point scale (in which 0 points mean that no nest was built, and 4 points mean a perfect nest was built), ${ }^{*} \mathrm{p}<0.034$ and ${ }^{* *} \mathrm{p}<0.005$ (respectively) between both groups/strains (Chi-square).

cellular responses when targeted by hallucinogenic drugs, and activation of the mGluR2 abolishes hallucinogen-specific signaling and behavioral responses (e.g. [5]-[7] [13]). Moreover, in line with results with these knockout mice, post-mortem analysis of the brains of untreated schizophrenics revealed increased expression of 5HT2As and decreased expression of mGluR2s. This research is leading to the preclinical and clinical evaluation of new putative therapeutic drugs (potential antipsychotics) acting as agonists of the mGluR2 (e.g. [5]-[7] [13]).

According to the previous evidence, the complete absence of expression of the mGluR2 receptor in prefrontal cortex, hippocampus and striatum of RHA-I rats (compared to expression levels in the same structures of RLA-I rats) appears to be an outstanding finding [113]. Such an observation, in conjunction with the increased 5-HT2A receptor expression in prefrontal cortex of RHA-I rats and with the schizophrenia-like profile of the RHA line/strain in other phenotypes (see above), are overall in line with studies performed with mGluR2 and 5HT2A knockout mice as well as with similar 5HT2A/mGluR2 expression profiles in prefrontal cortex of untreated schizophrenic patients (e.g. [5]-[7] [13]). Thus, psychogenetic selection of RHA-I rats has led to a sort of spontaneous "functional" mGluR2 knock-out and "schizophrenia-prone" rat model, displaying increased dopamine and serotonin (in particular receptors and areas) functioning, as well as an absence of mGluR2 expression (in schizophrenia-relevant structures), and presenting many behavioural phenotypes relevant for an animal model of schizophrenia. 
Taken together, the above-mentioned findings point to the RHA-I rat strain as a promising genetic analogue for schizophrenia-relevant symptoms and underlying neurochemical mechanisms. Provided the particular profile of 5HT2A/mGluR2 expression in RHA-I rats, testing the hyper-locomotor and PPI-disrupting effects (as well as in models/tests other than PPI) of psychotomimetic drugs (i.e. 5HT2A agonists, such as LSD) and the reversal of such effects by typical (e.g. haloperidol) and atypical antipsychotics (e.g. clozapine, olanzapine) will be critical to get support for the predictive validity of the model. In addition, RHA-I rats (and their RLA-I counterparts) offer the possibility, for the first time, of studying the relationships among several neurochemical/molecular mechanisms, including the 5HT2A/mGluR2 complex (and associated downstream signalling pathways), and performance in relevant behavioural schizophrenia-related phenotypes (e.g. PPI, latent inhibition, and others), both in naive and in (pharmacologically- or environmentally-) treated RHA-I/RLA-I animals.

\section{Conclusions}

Most of the psychogenetic (or pharmacogenetic) rat models discussed in the present work appear to present good face validity, as they often show hyperlocomotion and/or enhanced locomotor responses to DA agonists (or psychostimulant drugs), impairments in PPI, and in some cases also impaired latent inhibition and/or deficits in some cognitive/executive functions. Some of them also present changes in mesolimbic dopamine function that are compatible with some construct validity. In this connection, construct validity is still better in those models presenting decreased neuregulin-1 methylation (i.e. the selectively bred low-PPI rat line) or alterations of both 5-HT2A receptors in frontal cortex and mGluR2 expression in frontal cortex, hippocampus and striatum (this is the case of the RHA-I rat strain). These models deserve further investigation of these neurochemical mechanisms and their relationship with the schizophrenia-relevant symptoms of these rat lines/strains.

On the other hand, the increased sensitivity to psychostimulant (i.e. AMPH) effects, or to dopamine agonist (i.e. APO) effects of some of these genetically selected rat strains (e.g. SHR, APO-SUS, RHA), are findings that give some support to their predictive validity. There have been few cases (e.g. low-PPI rat line, SHR, APO-SUS) in which antipsychotic drug effects on the main symptoms/deficits have been tested, with some successful results that strengthen the predictive validity of these lines/strains as models of schizophrenia. However, it is clear that there is still a long way to systematically explore (e.g. through psychotomimetic and antipsycotic drug treatments) the predictive validity of all the genetic rat models discussed in this review before one can conclude that some of them can be useful for searching new treatments for the disorder.

Genetic technology in mice has progressed much faster than in rats. Thus, a variety of genetically manipulated mouse models have been generated aiming at elucidating the relationship between individual genes (and processes derived from them) and particular symptoms or endophenotypes of schizophrenia. These knockouts/ transgenics rarely mimic many schizophrenia-relevant symptoms, and their utility is somewhat limited by neurodevelopmental changes that come to interact as compensatory mechanisms generated by the genetic manipulation. While waiting for reliable and efficient rat genetic technology, which could allow the generation of knockout or transgenic rats for hypothetical schizophrenia-related genes, the above-mentioned selective breeding procedures developed in rats have produced animals that often mimic several schizophrenia-relevant symptoms (which is not so common when using knockout mice). Moreover, the "normal" selection (or variation) of traits/ phenotypes and gene-environment interactions in humans are better (and more realistically) mimicked by selective breeding on the basis of values of a given phenotype (which often involve the co-selection of related phenotypes, as seen in some of the rat strains reviewed here) than by knockout or transgenic mice.

Some of the selected rat strains we have reviewed in this article present symptoms and neurobiological alterations that make them promising tools as models for schizophrenia-relevant features. We believe that future research should especially focus on, 1) drug treatment studies to see whether these models present also good predictive validity, and 2) on genetic mapping and differential genetic expression profiles of (selected) rats presenting extremely divergent symptoms/phenotypes or clusters of them, in order to evaluate associations among particular genes and schizophrenia-relevant (endo)phenotypes.

\section{Acknowledgements}

Supported by grants for the MICINN (PSI2009-10532), “Fundació La Maratò TV3” (ref. 092630/31) and 2009SGR0051. I.O. is recipient of a PhD FI fellowship (DGR 2014). 


\section{References}

[1] Sawa, A. and Snyder, S. (2002) Schizophrenia: Diverse Approaches to a Complex Disease. Science, 296, $692-695$. http://dx.doi.org/10.1126/science.1070532

[2] Powell, C.M. and Miyakawa, T. (2006) Schizophrenia-Relevant Behavioral Testing in Rodent Models: A Uniquely Human Disorder? Biological Psychiatry, 59, 1198-207. http://dx.doi.org/10.1016/j.biopsych.2006.05.008

[3] Jones, C.A., Watson, D.J.G. and Fone, K.C.F. (2011) Animal Models of Schizophrenia. British Journal of Pharmacology, 164, 1162-1194. http://dx.doi.org/10.1111/j.1476-5381.2011.01386.X

[4] Kapur, S. (2003) Psychosis as a State of Aberrant Salience: A Framework Linking Biology, Phenomenology, and Pharmacology in Schizophrenia. The American Journal of Psychiatry, 160, 13-23. http://dx.doi.org/10.1176/appi.ajp.160.1.13

[5] Gonzalez-Maeso, J., Ang, R., Yuen, T., Chan, P., Weisstaub, N.V., Lopez-Gimenez, J.F., et al. (2008) Identification of a Serotonin/Glutamate Receptor Complex Implicated in Psychosis. Nature, 452, 93-97. http://dx.doi.org/10.1038/nature06612

[6] Snyder, S.H. (2008) A Complex in Psychosis. Nature, 452, 38-39. http://dx.doi.org/10.1038/452038a

[7] Gonzalez-Maeso, J. and Sealfon, S.C. (2009) Psychedelics and Schizophrenia. Trends in Neurosciences, 32, $225-232$. http://dx.doi.org/10.1016/j.tins.2008.12.005

[8] Patil, S.T., Zhang, L., Martenyi, F., Lowe, S.L., Jackson, K.A., Andreev, B.V., et al. (2007) Activation of mGlu2/3 Receptors as a New Approach to Treat Schizophrenia: A Randomized Phase 2 Clinical Trial. Nature Medicine, 13, 1102-1107. http://dx.doi.org/10.1038/nm1632

[9] Geyer, M.A., Olivier, B., Joels, M. and Kahn, RS. (2012) From Antipsychotic to Anti-Schizophrenia Drugs: Role of Animal Models. Trends in Pharmacological Sciences, 33, 515-521. http://dx.doi.org/10.1016/j.tips.2012.06.006

[10] Fernando, A.B. and Robbins, T.W. (2011) Animal Models of Neuropsychiatric Disorders. Annual Reviews of Clinical Psychology, 7, 39-61. http://dx.doi.org/10.1146/annurev-clinpsy-032210-104454

[11] Morris, R. (1984) Developments of a Water-Maze Procedure for Studying Spatial Learning in the Rat. Journal of Neuroscience Methods, 11, 47-60. http://dx.doi.org/10.1016/0165-0270(84)90007-4

[12] Steele, R.J. and Morris, R.G. (1999) Delay-Dependent Impairment of a Matching-to-Place Task with Chronic and Intrahippocampal Infusion of the NMDA-Antagonist D-AP5. Hippocampus, 9, 118-136. http://dx.doi.org/10.1002/(SICI)1098-1063(1999)9:2<118::AID-HIPO4>3.0.CO;2-8

[13] Moreno, J.L. and González-Maeso, J. (2013) Preclinical Models of Antipsychotic Drug Action. The International Journal of Neuropsychopharmacology, 16, 2131-2144. http://dx.doi.org/10.1017/S1461145713000606

[14] Swerdlow, N.R., Geyer, M. and Braff, D. (2001) Neural Circuit Regulation of Prepulse Inhibition of Startle in the Rat: Current knowledge and future challenges. Psychopharmacology, 156, 194-215. http://dx.doi.org/10.1007/s002130100799

[15] Braff, D.L. and Geyer, M.A. (1990). Sensorimotor Gating and Schizophrenia: Human and Animal Model Studies. Archive of General Psychiatry, 47, 181-188. http://dx.doi.org/10.1001/archpsyc.1990.01810140081011

[16] Geyer, M.A. and Swerdlow, N.R. (2001) Measurement of Startle Response, Prepulse Inhibition and Habituation. Current Protocols in Neuroscience, 3, 8.7.1-8.7.15.

[17] Powell, S.B., Weber, M. and Geyer, M. (2012) Genetic Models of Sensorimotor Gating: Relevance to Neuropsychiatric Disorders. Current Topics in Behavioral Neuroscience, 12, 251-318. http://dx.doi.org/10.1007/7854_2011_195

[18] Ellenbroek, B.A., Geyer, M.A. and Cools, A.R. (1995) The Behavior of APO-SUS Rats in Animal Models with Construct Validity for Schizophrenia. Journal of Neuroscience, 15, 7604-7611.

[19] Shalev, U., Feldon, J. and Weiner, I. (1998) Gender- and Age-Dependent Differences in Latent Inhibition Following Pre-Weaning Non-Handling: Implications for a Neurodevelopmental Animal Model of Schizophrenia. International Journal of Developmental Neuroscience, 16, 279-288. http://dx.doi.org/10.1016/S0736-5748(98)00031-8

[20] Fernández-Teruel, A., Blázquez, G., Pérez, M., Aguilar, R., Cañete, T., Guitart-Masip, M., et al. (2006) Latent Inhibition Threshold in Roman High-Avoidance Rats: A Psychogenetic Model of Abnormalities in Attentional Filter? Actas Españolas de Psiquiatría, 34, 257-263.

[21] Palmer, A.A. and Printz, M.P. (1999) Strain Differences in Fos Expression Following Airpuff Startle in Spontaneously Hypertensive and Wistar Kyoto Rats. Neuroscience, 89, 965-978. http://dx.doi.org/10.1016/S0306-4522(98)00333-9

[22] Swerdlow, N.R., Martinez, Z.A., Hanlon, F.M., Platten, A., Farid, M., Auerbach, P., Braff, D.L. and Geyer, M.A. (2000) Towards Understanding the Biology of a Complex Phenotype: Rat Strain and Substrain Differences in the Sensorimotor Gating-Disruptive Effects of Dopamine Agonists. The Journal of Neuroscience, 20, 4325-4336.

[23] Swerdlow, N.R., Shoemaker, J.M., Platten, A., Pitcher, L., Goins, J. and Crain, S. (2003) Heritable Differences in the 
Effects of Amphetamine but Not DOI on Startle Gating in Albino and Hooded Outbred Rat Strains. Pharmacology Biochemistry and Behavior, 75, 191-197. http://dx.doi.org/10.1016/S0091-3057(03)00078-9

[24] Swerdlow, N.R., Shoemaker, J.M., Platten, A., Pitcher, L., Goins, J. and Auerbach, P.P. (2004) Heritable Differences in the Dopaminergic Regulation of Sensorimotor Gating. I. Apomorphine Effects on Startle Gating in Albino and Hooded Outbred Rat Strains and their F1 and N2 Progeny. Psychopharmacology, 174, 441-451. http://dx.doi.org/10.1007/s00213-003-1481-3

[25] Swerdlow, N.R., Varty, G.B. and Geyer, M.A. (1998) Discrepant Findings of Clozapine Effects on Prepulse Inhibition of Startle: Is It the Route or the Rat? Neuropsychopharmacology, 18, 50-56. http://dx.doi.org/10.1016/S0893-133X(97)00110-3

[26] Swerdlow, N.R., Platten, A., Kim, Y.K., Gaudet, I., Shoemaker, J., Pitcher, L. and Auerbach, P. (2001) Sensitivity to the Dopaminergic Regulation of Prepulse Inhibition in Rats: Evidence for Genetic, but Not Environmental Determinants. Pharmacology, Biochemistry and Behavior, 70, 219-226. http://dx.doi.org/10.1016/S0091-3057(01)00598-6

[27] Swerdlow,N.R., Platten, A., Hanlon, F.M., Martinez, Z.A., Printz, M.P. and Auerbach, P. (2003) Sensitivity to Sensorimotor Gating-Disruptive Effects of Apomorphine in Two Outbred Parental Rat Strains and their F1 and N2 Progeny. Neuropsychopharmacology, 28, 226-234.http://dx.doi.org/10.1038/sj.npp.1300035

[28] Swerdlow, N.R., Shilling, P.D., Breier, M., Trim, R.S., Light, G.A. and Saint Marie, R.L. (2012) Fronto-TemporalMesolimbic Gene Expression and Heritable Differences in Amphetamine-Disrupted Sensorimotor Gating in Rats. Psychopharmacology, 224, 349-362. http://dx.doi.org/10.1007/s00213-012-2758-1

[29] Overstreet, D.H., Moy, S.S., Lubin, D.A., Gause, L.R., Lieberman, J.A. and Johns, J.M. (2000) Enduring Effects of Prenatal Cocaine Administration on Emotional Behavior in Rats. Physiology \& Behavior, 70, 149-156. http://dx.doi.org/10.1016/S0031-9384(00)00245-6

[30] Vaillancourt, C. and Boksa, P. (2000) Birth Insult Alters Dopamine-Mediated Behavior in a Precocial Species, the Guinea Pig: Implications for Schizophrenia. Neuropsychopharmacology, 23, 654-666. http://dx.doi.org/10.1016/S0893-133X(00)00164-0

[31] Sontag, T.A., Cools, A.R. and Ellenbroek, B.A. (2003) Removal of Short-Term Isolation Stress Differentially Influences Prepulse Inhibition in APO-SUS and APO-UNSUS Rats. Behavioural Brain Research, 141, 171-175. http://dx.doi.org/10.1016/S0166-4328(02)00364-9

[32] Aguilar, R., Gil, L., Tobeña, A., Escorihuela, R.M. and Fernández-Teruel, A. (2000) Differential Effects of Cohort Removal Stress on the Acoustic Startle Response of the Roman/Verh Rat Strains. Behavior Genetics, 30, 71-75. http://dx.doi.org/10.1023/A:1002042711672

[33] Birkett, S.D. and Pickering, B.T. (1988) The Vasopressin Precursor in the Brattleboro (di/di) Rat. International Journal of Peptide and Protein Research, 32, 565-572. http://dx.doi.org/10.1111/j.1399-3011.1988.tb01388.x

[34] Feifel, D. and Priebe, K. (2001) Vasopressin-Deficient Rats Exhibit Sensorimotor Gating Deficits that Are Reversed by Subchronic Haloperidol. Biological Psychiatry, 50, 425-433. http://dx.doi.org/10.1016/S0006-3223(01)01100-3

[35] Feifel, D., Mexal, S., Melendez, G., Liu, P.Y., Goldenberg, J.R. and Shilling, P.D. (2009) The Brattleboro Rat Displays a Natural Deficit in Social Discrimination That Is Restored by Clozapine and a Neurotensin Analog. Neuropsychopharmacology, 34, 2011-2018. http://dx.doi.org/10.1038/npp.2009.15

[36] Feifel, D., Shilling, P.D. and Melendez, G. (2011) Further Characterization of the Predictive Validity of the Brattleboro Rat Model for Antipsychotic Efficacy. Journal of Psychopharmacology, 25, 836-841. http://dx.doi.org/10.1177/0269881110388327

[37] Feifel, D. and Priebe, K. (2007) The Effects of Cross-Fostering on Inherent Sensorimotor Gating Deficits Exhibited by Brattleboro Rats. The Journal of General Psychology, 134, 173-182. http://dx.doi.org/10.3200/GENP.134.2.172-182

[38] Berquist, M.D., Mooney-Leber, S.M., Feifel, D. and Prus, A.J. (2013) Assessment of Attention in Male and Female Brattleboro Rats Using a Self-Paced Five-Choice Serial Reaction Time Task. Brain Research, 1537, 174-179. http://dx.doi.org/10.1016/j.brainres.2013.09.012

[39] Cilia, J., Gartlon, J.E., Shilliam, C., Dawson, L.A., Moore, S.H. and Jones, D.N. (2010) Further Neurochemical and Behavioural Investigation of Brattleboro Rats as a Putative Model of Schizophrenia. Journal of Psychopharmacology, 24, 407-419. http://dx.doi.org/10.1177/0269881108098787

[40] Brito, G.N., Thomas, G.J., Gash, D.M. and Kitchen, J.H. (1982) The Behavior of Brattleboro Rats. Annals of the New York Academy of Sciences, 394, 740-748. http://dx.doi.org/10.1111/j.1749-6632.1982.tb37492.x

[41] Laycock, J.F., Gartside, I.B. and Chapman, J.T. (1983) A Comparison of the Learning Abilities of Brattleboro Rats with Hereditary Diabetes Insipidus and Long-Evans Rats Using Positively Reinforced Operant Conditioning. Progress in Brain Research, 60, 183-187. http://dx.doi.org/10.1016/S0079-6123(08)64385-X

[42] Shilling, P.D., Kinkead, B., Murray, T., Melendez, G., Nemeroff, C.B. and Feifel, D. (2006) Upregulation of Striatal Dopamine-2 Receptors in Brattleboro Rats with Prepulse Inhibition Deficits. Biological Psychiatry, 60, 1278-1281. 
http://dx.doi.org/10.1016/j.biopsych.2006.03.045

[43] Sagvolden, T., Metzger, M.A., Schiorbeck, H.K., Rugland, A.L., Spinnangr, I. and Sagvolden, G. (1992) The Spontaneously Hypertensive Rat (SHR) as an Animal Model of Childhood Hyperactivity (ADHD): Changed Reactivity to Reinforcers and to Psychomotor Stimulants. Behavioral and Neural Biology, 58, 103-112. http://dx.doi.org/10.1016/0163-1047(92)90315-U

[44] Russel, V.A. (2007) Neurobiology of Animal Models of Attention-Deficit Hyperactivity Disorder. Journal of Neuroscience Methods, 166, 1-14. http://dx.doi.org/10.1016/j.jneumeth.2006.12.020

[45] Calzavara, M.B., Levin, R., Medrano, W.A., Almeida, V., Sampaio, A.P., Barone, L.C., et al. (2011) Effects of Antipsychotics and Amphetamine on Social Behaviors in Spontaneously Hypertensive Rats. Behavioural Brain Research, 225, 15-22. http://dx.doi.org/10.1016/j.bbr.2011.06.026

[46] Calzavara, M.B., Medrano, W.A., Levin, R., Kameda, S.R., Andersen, M.L., Tufik, S., et al. (2009) Neuroleptic Drugs Revert the Contextual Fear Conditioning Deficit Presented by Spontaneously Hypertensive Rats: A Potential Animal Model of Emotional Context Processing in Schizophrenia? Schizophrenia Bulletin, 35, 748-759. http://dx.doi.org/10.1093/schbul/sbn006

[47] Ferguson, S.A. and Cada, A.M. (2004) Spatial Learning/Memory and Social and Nonsocial Behaviors in the Spontaneously Hypertensive, Wistar-Kyoto and Sprague-Dawley Rat Strains. Pharmacology Biochemistry and Behavior, 77, 583-594. http://dx.doi.org/10.1016/j.pbb.2003.12.014

[48] Levin, R., Peres, F.F., Almeida, V., Calzavara, M.B., Zuardi, A.W., Hallak, J.E., et al. (2014) Effects of Cannabinoid Drugs on the Deficit of Prepulse Inhibition of Startle in an Animal Model of Schizophrenia: The SHR Strain. Frontiers in Pharmacology, 5, 10. http://dx.doi.org/10.3389/fphar.2014.00010

[49] van den Buuse, M. (2004) Prepulse Inhibition of Acoustic Startle in Spontaneously Hypertensive Rats. Behavioural Brain Research, 154, 331-337. http://dx.doi.org/10.1016/j.bbr.2004.02.021

[50] Lipska, B.K. and Weinberger, D.R. (2000) To Model a Psychiatric Disorder in Animals: Schizophrenia as a Reality Test. Neuropsychopharmacology, 23, 223-239. http://dx.doi.org/10.1016/S0893-133X(00)00137-8

[51] Sams-Dodd, F. (1998) A Test of the Predictive Validity of Animal Models of Schizophrenia Based on Phencyclidine and D-Amphetamine. Neuropsychopharmacology, 18, 293-304. http://dx.doi.org/10.1016/S0893-133X(97)00161-9

[52] Freudenberg, F., Dieckmann, M., Winter, S., Koch, M. and Schwabe, K. (2007) Selective Breeding for Deficient Sensorimotor Gating Is Accompanied by Increased Perseveration in Rats. Neuroscience, 148, 612-622. http://dx.doi.org/10.1016/j.neuroscience.2007.06.034

[53] Schwabe, K., Freudenberg, F. and Koch, M. (2007) Selective Breeding of Reduced Sensorimotor Gating in Wistar Rats. Behavior Genetics, 37, 706-712. http://dx.doi.org/10.1007/s10519-007-9166-z

[54] Cook, D. and Kesner, R.P. (1998) Caudate Nucleus and Memory for Egocentric Localization. Behavioral and Neural Biology, 49, 332-343. http://dx.doi.org/10.1016/S0163-1047(88)90338-X

[55] Kesner, R.P., Bolland, B.L. and Dakis, M. (1993) Memory for Spatial Locations, Motor Responses, and Objects: Triple Dissociations among the Hippocampus, Caudate Nucleus, and Extrastriate Visual Cortex. Experimental Brain Research, 93, 462-470. http://dx.doi.org/10.1007/BF00229361

[56] Hanlon, F.M. and Sutherland, R.J. (2000) Changes in Adult Brain and Behavior Caused by Neonatal Limbic Damage: Implications for the Etiology of Schizophrenia. Behavioural Brain Research, 107, 71-83. http://dx.doi.org/10.1016/S0166-4328(99)00114-X

[57] Chang, Q. and Gold, P.E. (2003) Intra-Hippocampal Lidocaine Injections Impair Acquisition of a Place Task and Facilitate Acquisition of a Response Task in Rats. Behavioural Brain Research, 144, 19-24. http://dx.doi.org/10.1016/S0166-4328(03)00063-9

[58] Lysaker, P.H., Bell, M.D., Bryson, G. and Kaplan, E. (1998) Neurocognitive Function and Insight in Schizophrenia: Support for an Association with Impairments in Executive Function. Acta Psychiatrica Scandinavica, 97, $297-301$. http://dx.doi.org/10.1111/j.1600-0447.1998.tb10003.x

[59] Perry, W. and Braff, D.L. (1998) A Multimethod Approach to Assessing Perseverations in Schizophrenia Patients. Schizophrenia Research, 33, 69-77. http://dx.doi.org/10.1016/S0920-9964(98)00061-9

[60] Dieckmann, M., Freudenberg, F., Klein, S., Koch, M. and Schwabe, K. (2007) Disturbed Social Behaviour and Motivation in Rats Selectively Bred for Deficient Sensorimotor Gating. Schizophrenia Research, 97, 250-253. http://dx.doi.org/10.1016/j.schres.2007.08.007

[61] Hadamitzky, M., Harich, S., Koch, M. and Schwabe, K. (2007) Deficient Prepulse Inhibition Induced by Selective Breeding of Rats Can Be Restored by the Dopamine D2 Antagonist Haloperidol. Behavioural Brain Research, 177, 364-367. http://dx.doi.org/10.1016/j.bbr.2006.11.037

[62] Rhein, M., Muschler, M.R., Krauss, J.K., Bleich, S., Frieling, H. and Schwabe, K. (2013) Hypomethylation of Neure- 
gulin in Rats Selectively Bred for Reduced Sensorimotor Gating. Schizophrenia Research, 150, 262-265. http://dx.doi.org/10.1016/j.schres.2013.07.012

[63] Weickert, C.S., Tiwari, Y., Schofield, P.R., Mowry, B.J. and Fullerton, J.M. (2012) Schizophrenia-Associated HapICE Haplotype Is Associated with Increased NRG1 Type III Expression and High Nucleotide Diversity. Translational Psychiatry, 2, e104. http://dx.doi.org/10.1038/tp.2012.25

[64] Petrovszki, Z., Adam, G., Tuboly, G., Kekesi, G., Benedek, G., Keri, S., et al. (2013) Characterization of Gene-Environment Interactions by Behavioral Profiling of Selectively Bred Rats: The Effect of NMDA Receptor Inhibition and Social Isolation. Behavioural Brain Research, 240, 134-145. http://dx.doi.org/10.1016/j.bbr.2012.11.022

[65] Cools, A.R., Brachten, R., Heeren, D., Willemen, A. and Ellenbroek, B. (1990) Search after Neurobiological Profile of Individual-Specific Features of Wistar Rats. Brain Research Bulletin, 18, 663-669.

[66] Ellenbroek, B.A., Geyer, M.A. and Cools, A.R. (1995) The Behavior of APO-SUS Rats in Animal Models with Construct Validity for Schizophrenia. Journal of Neuroscience, 15, 7604-7611.

[67] Ellenbroek, B.A. and Cools, A. (2002) Apomorphine Susceptibility and Animal Models for Psycopathology: Genes and Environment. Behavior Genetics, 32, 349-361. http://dx.doi.org/10.1023/A:1020214322065

[68] Cabib, S., Oliverio, A., Ventura, R., Luchesse, F. and Puglisi, A. (1997) Brain Dopamine Receptor Plasticity: Testing a Diathesis-Stress Hypothesis in an Animal Model. Psychopharmacology, 132, 153-160. http://dx.doi.org/10.1007/s002130050331

[69] Ellenbroek, B.A., Sluyter, F. and Cools, A. (2000) The Role of Genetic and Early Environmental Factors in Determining Apomorphine Susceptibility. Psychopharmacology, 148, 124-131. http://dx.doi.org/10.1007/s002130050033

[70] Cools, A.R., Ellenbroek, B.A., Gingras, M.A., Engbersen, A. and Heeren, D. (1997) Differences in Vulnerability and Susceptibility to Dexamphetamine in Nijmegen High and Low Responders to Novelty: A Dose-Effect Analysis of SpatioTemporal Programming of Behaviour. Psychopharmacology, 132, 181-187. http://dx.doi.org/10.1007/s002130050334

[71] Van der Elst, M.C., Ellenbroek, B.A. and Cools, A.R. (2006) Cocaine Strongly Reduces Prepulse Inhibition in Apomorphine-Susceptible Rats, but Not in Apomorphine-Unsusceptible Rats: Regulation by Dopamine D2 Receptors. Behavioural Brain Research, 175, 392-398. http://dx.doi.org/10.1016/j.bbr.2006.09.014

[72] Aguilar, R., Gil, L., Fernández-Teruel, A. and Tobeña, A. (2000) Genetically-Based Behavioral Traits Influence the Effects of Shuttle Box Avoidance Overtraining and Extinction upon Intertrial Responding: A Study with the Roman Rat Strains. Behavioural Processes, 66, 63-72. http://dx.doi.org/10.1016/j.beproc.2004.01.002

[73] Bignami, G. (1965) Selection for High Rates and Low Rates of Avoidance Conditioning in the Rat. Animal Behaviour, 13, 221-227. http://dx.doi.org/10.1016/0003-3472(65)90038-2

[74] Driscoll, P. and Bättig, K. (1982) Behavioural, Emotional and Neurochemical Profiles of Rats Selected for Extreme Differences in Active, Two-Way Avoidance Performance. In: Lieblich, I., Ed., Genetics of the Brain, Elsevier, Amsterdam, 95-123.

[75] Driscoll, P., Escorihuela, R.M., Fernández-Teruel, A., Giorgi, O., Schwegler, H., Steimer, T.H., et al. (1998) Genetic Selection and Differential Stress Responses: The Roman Lines/Strain of Rats. Annals of the New York Academy of Sciences, 851, 501-510.

[76] Driscoll, P., Fernández-Teruel, A., Corda, M.G., Giorgi, O. and Steimer, T. (2009) Some Guidelines for Defining Personality Differences in Rats. In: Yong-Kyu, K., Ed., Handbook of Behavior Genetics, Springer, New York, 281-300. http://dx.doi.org/10.1007/978-0-387-76727-7 20

[77] Escorihuela, R.M., Tobeña, A., Driscoll, P. and Fernández-Teruel, A. (1995) Effects of Training, Early Handling, and Perinatal Flumazenil on Shuttle Box Acquisition in Roman Low-Avoidance Rats: Toward Overcoming a Genetic Deficit. Neuroscience \& Biobehavioral Reviews, 19, 353-367. http://dx.doi.org/10.1016/0149-7634(94)00051-2

[78] Escorihuela, R.M., Fernández-Teruel, A., Gil, L., Aguilar, R., Tobeña, A. and Driscoll, P. (1999) Inbred Roman Highand Low-Avoidance Rats Differences in Anxiety, Novelty Seeking, and Shuttlebox Behaviors. Physiology \& Behavior, 67, 19-26. http://dx.doi.org/10.1016/S0031-9384(99)00064-5

[79] Fernandez-Teruel, A., Escorihuela, R.M., Castellano, B., Gonzalez, B. and Tobeña, A. (1997) Neonatal Handling and Environmental Enrichment Effects on Emotionality, Novelty/Reward Seeking, and Age-Related Cognitive and Hippocampal Impairments: Focus on the Roman Rat Lines. Behavior Genetics, 27, 513-526. http://dx.doi.org/10.1023/A:1021400830503

[80] López-Aumatell, R., Vicens-Costa, E., Guitart-Masip, M., Martínez-Membrives, E., Valdar, W., Johannesson, M., et al. (2009) Unlearned Anxiety Predicts Learned Fear: A Comparison among Heterogeneous Rats and the Roman Rat Strains. Behavioural Brain Research, 202, 92-101. http://dx.doi.org/10.1016/j.bbr.2009.03.024

[81] López-Aumatell, R., Vicens-Costa, E., Guitart-Masip, M., Martínez-Membrives, E., Valdar, W., Johannesson, M., et al. (2009) Ansiedad en Ratas Genéticamente Heterogéneas: Hacia la Identificación de Genes para Caracteres Conduc- 
tuales Cuantitativos. Ansiedad y Estrés, 15, 67-84.

[82] Diaz-Moran, S., Palència, M., Mont-Cardona, C., Cañete, T., Blázquez, G., Martínez-Membrives, E., et al. (2012) Coping Style and Stress Hormone Responses in Genetically Heterogeneous Rats: Comparison with the Roman Rat Strains. Behavioural Brain Research, 228, 203-210. http://dx.doi.org/10.1016/j.bbr.2011.12.002

[83] Díaz-Morán, S., Martínez-Membrives, E., López-Aumatell, R., Cañete, T., Blázquez, G., Palencia, M., et al. (2013) What Can We Learn on Rodent Fearfulness/Anxiety from the Genetically Heterogeneous NIH-HS Rat Stock? Open Journal of Psychiatry, 3, 238-250. http://dx.doi.org/10.4236/ojpsych.2013.32022

[84] Estanislau, C., Díaz-Morán, S., Cañete, T., Blázquez, G., Tobeña, A. and Fernández-Teruel, A. (2013) Context-Dependent Differences in Grooming Behavior among the NIH Heterogeneous Stock and the Roman High- and LowAvoidance Rats. Neuroscience Research, 77, 187-201. http://dx.doi.org/10.1016/j.neures.2013.09.012

[85] Carrasco, J., Márquez, C., Nadal, R., Tobeña, A., Fernández-Teruel, A. and Armario, A. (2008) Characterization of Central and Peripheral Components of the Hypothalamus-Pituitary-Adrenal Axis in the Inbred Roman Rat Strains. Psychoneuroendocrinology, 33, 437-445. http://dx.doi.org/10.1016/j.psyneuen.2008.01.001

[86] Steimer, T. and Driscoll, P. (2003) Divergent Stress Responses and Coping Styles in Psychogenetically Selected Roman High-(RHA) and Low-(RLA) Avoidance Rats: Behavioural, Neuroendocrine and Developmental Aspects. Stress, 6, 87-100. http://dx.doi.org/10.1080/1025389031000111320

[87] Steimer, T. and Driscoll, P. (2005) Inter-Individual vs Line/Strain Differences in Psychogenetically Selected Roman High-(RHA) and Low-(RLA) Avoidance Rats: Neuroendocrine and Behavioural Aspects. Neuroscience \& Biobehavioral Reviews, 29, 99-112. http://dx.doi.org/10.1016/j.neubiorev.2004.07.002

[88] Schwegler, H., Pilz, P.K.D., Koch, M., Fendt, M., Linke, R. and Driscoll, P. (1997) The Acoustic Startle Response in Inbred Roman High- and Low-Avoidance Rats. Behavior Genetics, 27, 579-581.

[89] Fernandez-Teruel, A., Escorihuela, R.M., Driscoll, P., Tobeña, A. and Bättig, K. (1991) Infantile (Handling) Stimulation and Behavior in Young Roman High- and Low-Avoidance Rats. Physiology \& Behavior, 50, 563-565. http://dx.doi.org/10.1016/0031-9384(91)90546-Z

[90] Fernandez-Teruel, A., Escorihuela, R.M., Nuñez, J.F., Gomá, M., Driscoll, P. and Tobeña, A. (1992) Early Stimulation Effects on Novelty-Induced Behavior in Two Psychogenetically-Selected Rat Lines with Divergent Emotionality Profiles. Neuroscience Letters, 137, 185-188. http://dx.doi.org/10.1016/0304-3940(92)90400-2

[91] Ferré, P., Fernández-Teruel, A., Escorihuela, R.M., Driscoll, P., Corda, M.G., Giorgi, O., et al. (1995) Behavior of the Roman/Verh High- and Low-Avoidance Rat Lines in Anxiety Tests: Relationship with Defecation and Self-Grooming. Physiology \& Behavior, 58, 1209-1213. http://dx.doi.org/10.1016/0031-9384(95)02068-3

[92] López-Aumatell, R., Blázquez, G., Gil, L., Aguilar, R., Cañete, T., Giménez-Llort, L., et al. (2009) The Roman Highand Low-Avoidance Rat Strains Differ in Fear-Potentiated Startle and Classical Aversive Conditioning. Psicothema, 21, 27-32.

[93] Yilmazer-Hanke, D.M., Faber-Zuschratter, H., Linke, R. and Schwegler, H. (2002) Contribution of Amygdala Neurons Containing Peptides and Calcium-Binding Proteins to Fear-Potentiated Startle and Exploration-Related Anxiety in Inbred Roman High- and Low-Avoidance Rats. European Journal of Neuroscience, 15, 1206-1218. http://dx.doi.org/10.1046/j.1460-9568.2002.01945.x

[94] Manzo, L., Gómez, M.J., Callejas-Aguilera, J.E., Fernández-Teruel, A., Papini, M.R. and Torres, C. (2014) AntiAnxiety Self-Medication Induced by Incentive Loss in Rats. Physiology \& Behavior, 123, 86-92. http://dx.doi.org/10.1016/j.physbeh.2013.10.002

[95] Corda, M.G., Lecca, D., Piras, G., Di Chiara, G. and Giorgi, O. (1997) Biochemical Parameters of Dopaminergic and Gabaergic Neurotransmission in the CNS of Roman High-Avoidance and Roman Low-Avoidance Rats. Behavior Genetics, 27, 527-536. http://dx.doi.org/10.1023/A:1021452814574

[96] Escorihuela, R.M., Tobena, A. and Fernandez-Teruel, A. (1995) Environmental Enrichment and Postnatal Handling Prevent Spatial Learning Deficits in Aged Hypoemotional (Roman High-Avoidance) and Hyperemotional (Roman Low-Avoidance) Rats. Learning and Memory, 2, 40-48. http://dx.doi.org/10.1101/lm.2.1.40

[97] Escorihuela, R.M., Fernández-Teruel, A., Tobeña, A., Langhans, W., Bättig, K. and Driscoll, P. (1997) Labyrinth Exploration, Emotional Reactivity, and Conditioned Fear in Young Roman/Verh Inbred Rats. Behavior Genetics, 27, 573578. http://dx.doi.org/10.1023/A:1021413200461

[98] Aguilar, R., Escorihuela, R.M., Gil, L., Tobeña, A. and Fernández-Teruel, A. (2002) Differences between Two Psychogenetically Selected Lines of Rats in a Swimming Pool Matching-to-Place Task: Long-Term Effects of Infantile Stimulation. Behavior Genetics, 32, 127-134. http://dx.doi.org/10.1023/A:1015253807488

[99] Moreno, M., Cardona, D., Gómez, M.J., Sánchez-Santed, F., Tobeña, A., Fernández-Teruel, A., et al. (2010) Impulsivity Characterization in the Roman High- and Low-Avoidance Rat Strains: Behavioral and Neurochemical Differences. Neuropsychopharmacology, 35, 1198-1208. http://dx.doi.org/10.1038/npp.2009.224 
[100] Driscoll, P., Ferré, P., Fernández-Teruel, A., Levi de Stein, M., Wolfman, C., Medina, J., et al. (1995) Effects of Prenatal Diazepam on Two-Way Avoidance Behavior, Swimming Navigation and Brain Levels of Benzodiazepine-Like Molecules in Male Roman High- and Low-Avoidance Rats. Psychopharmacology, 122, 51-57. http://dx.doi.org/10.1007/BF02246441

[101] Nil, R. and Bättig, K. (1981) Spontaneous Maze Ambulation and Hebb-Williams Learning in Roman High-Avoidance and Roman Low-Avoidance Rats. Behavioral and Neural Biology, 33, 465-475. http://dx.doi.org/10.1016/S0163-1047(81)91833-1

[102] Manzo, L., Gómez, M.J., Callejas-Aguilera, J.E., Donaire, R., Sabariego, M., Fernández-Teruel, A., et al. (2014) Relationship between Ethanol Preference and Sensation/Novelty Seeking. Physiology \& Behavior, 133, 53-60. http://dx.doi.org/10.1016/j.physbeh.2014.05.003

[103] Zeier, H., Baettig, K. and Driscoll, P. (1978) Acquisition of DRL-20 Behavior in Male and Female, Roman High- and Low-Avoidance Rats. Physiology \& Behavior, 20, 791-793. http://dx.doi.org/10.1016/0031-9384(78)90307-4

[104] Giorgi, O., Piras, G. and Corda, M.G. (2007) The Psychogenetically Selected Roman High- and Low-Avoidance Rat Lines: A Model to Study the Individual Vulnerability to Drug Addiction. Neuroscience \& Biobehavioral Reviews, 31, 148-163. http://dx.doi.org/10.1016/j.neubiorev.2006.07.008

[105] Fattore, L., Piras, G., Corda, M.G. and Giorgi, O. (2009) The Roman High- and Low-Avoidance Rat Lines Differ in the Acquisition, Maintenance, Extinction, and Reinstatement of Intravenous Cocaine Self-Administration. Neuropsychopharmacology, 34, 1091-1101. http://dx.doi.org/10.1038/npp.2008.43

[106] Corda, M.G., Piras, G., Lecca, D., Fernández-Teruel, A., Driscoll, P. and Giorgi, O. (2005) The Psychogenetically Selected Roman Rat Lines Differ in the Susceptibility to Develop Amphetamine Sensitization. Behavioural Brain Research, 157, 147-156. http://dx.doi.org/10.1016/j.bbr.2004.06.016

[107] Giorgi, O., Lecca, D., Piras, G., Driscoll, P. and Corda, M.G. (2003) Dissociation between Mesocortical Dopamine Release and Fear-Related Behaviours in Two Psychogenetically Selected Lines of Rats that Differ in Coping Strategies to Aversive Conditions. European Journal of Neuroscience, 17, 2716-2726. http://dx.doi.org/10.1046/j.1460-9568.2003.02689.x

[108] Sallés, J., López de Jesús, M., Goñi, O., Fernández-Teruel, A., Driscoll, P., Tobeña, A., et al. (2001) Transmembrane Signaling through Phospholipase C in Cortical and Hippocampal Membranes of Psychogenetically Selected Rat Lines. Psychopharmacology, 154, 115-125. http://dx.doi.org/10.1007/s002130000621

[109] Guitart-Masip, M., Johansson, B., Cañete, T., Fernández-Teruel, A., Tobeña, A., Terenius, L. and Giménez-Llort, L. (2008) Regional Adaptations in PSD-95, NGFI-A and Secretogranin Gene Transcripts Related to Vulnerability to Behavioral Sensitization to Amphetamine in the Roman Rat Strains. Neuroscience, 151, 195-208. http://dx.doi.org/10.1016/j.neuroscience.2007.09.072

[110] Garcia-Falgueras, A., Castillo-Ruiz, M.M., Put, T., Tobeña, A. and Fernández-Teruel, A. (2012) Differential Hippocampal Neuron Density between Inbred Roman High- (Low Anxious) and Low-Avoidance (High Anxious) Rats. Neuroscience Letters, 522, 41-46. http://dx.doi.org/10.1016/j.neulet.2012.06.011

[111] Meyza, K.Z., Boguszewski, P.M., Nikolaev, E. and Zagrodzka, J. (2009) Diverse Sensitivity of RHA/Verh and RLA/Verh Rats to Emotional and Spatial Aspects of a Novel Environment as a Result of a Distinct Pattern of Neuronal Activation in the Fear/Anxiety Circuit. Behavior Genetics, 39, 48-61. http://dx.doi.org/10.1007/s10519-008-9234-z

[112] Bentareha, R., Araujo, F., Ruano, D., Driscoll, P., Escorihuela, R.M., Tobeña, A., et al. (1998) Pharmacological Properties of the GABA(A) Receptor Complex from Brain Regions of (Hypoemotional) Roman High- and (Hyperemotional) Low-Avoidance Rats. European Journal of Pharmacology, 354, 91-97. http://dx.doi.org/10.1016/S0014-2999(98)00428-2

[113] Klein, A.B., Ultved, L., Adamsen, D., Santini, M.A., Tobeña, A., Fernandez-Teruel, A., et al. (2014) 5-HT $2 \mathrm{~A}$ and mGlu2 Receptor Binding Levels Are Related to Differences in Impulsive Behavior in the Roman Low- (RLA) and High- (RHA) Avoidance Rat Strains. Neuroscience, 263, 36-45. http://dx.doi.org/10.1016/j.neuroscience.2013.12.063

[114] Giménez-Llort, L., Cañete, T., Guitart-Masip, M., Fernández-Teruel, A. and Tobeña, A. (2005) Two Distinctive Apomorphine-Induced Phenotypes in the Roman High- and Low-Avoidance Rats. Physiology \& Behavior, 86, 458-466. http://dx.doi.org/10.1016/j.physbeh.2005.07.021

[115] Coppens, C.M., de Boer, S.F., Steimer, T. and Koolhaas, J.M. (2012) Impulsivity and Aggressive Behavior in Roman High and Low Avoidance Rats: Baseline Differences and Adolescent Social Stress Induced Changes. Physiology \& Behavior, 105, 1156-1160. http://dx.doi.org/10.1016/j.physbeh.2011.12.013

[116] Del Río, C., Oliveras, I., Cañete, T., Blázquez, G., Tobeña, A. and Fernández-Teruel, A. (2013) Déficits de Filtraje Atencional y en Funciones Ejecutivas en Ratas "Roman de Alta Evitacion” (RHA): Aproximación a un Modelo Animal de Esquizofrenia. Unpublished Master Thesis, Autonomous University of Barcelona, Cerdanyola del Vallès. 
Scientific Research Publishing (SCIRP) is one of the largest Open Access journal publishers. It is currently publishing more than 200 open access, online, peer-reviewed journals covering a wide range of academic disciplines. SCIRP serves the worldwide academic communities and contributes to the progress and application of science with its publication.

Other selected journals from SCIRP are listed as below. Submit your manuscript to us via either submit@scirp.org or Online Submission Portal.
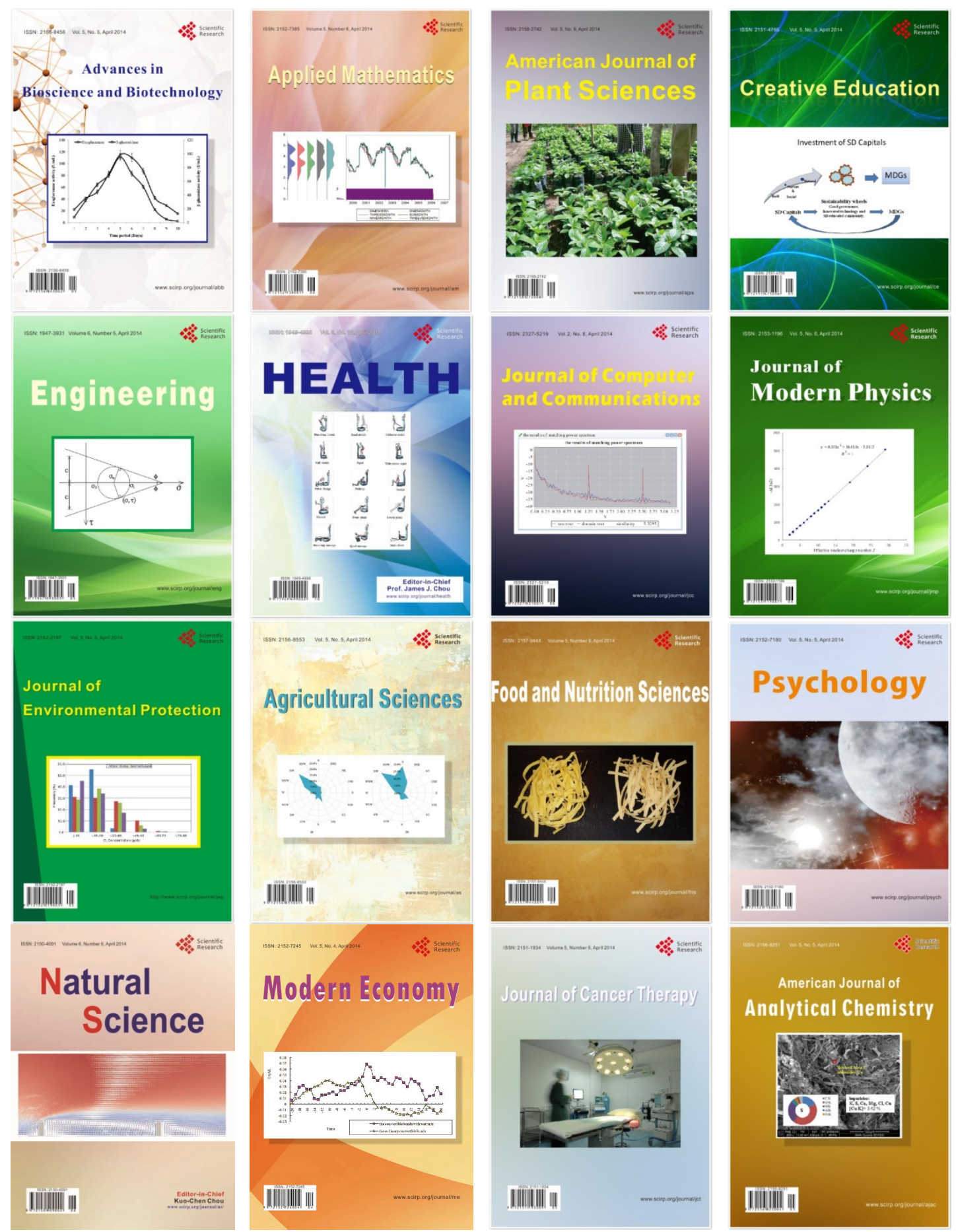